\title{
Contextualizando a autoimagem e a autoestima na realidade docente
}

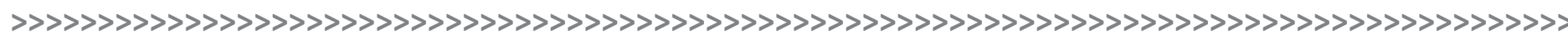

Karina Pacheco Dohms*

\begin{abstract}
Resumo:
O objetivo deste estudo foi investigar níveis de autoimagem e auto-estima de adolescentes que atuam em educação básica. A pesquisa quantitativa utilizou para a coleta de dados o Questionário de Autoimagem e Autoestima adaptado por Stobäus (1983) daquele elaborado por Steglich, em 1978. Participaram da pesquisa 25 docentes, com idades entre 26 e 58 anos, de uma escola tradicional de Porto Alegre, de ensino privado, que atuam três níveis de ensino (Educação Infantil, Ensino Fundamental e Médio). Os dados foram analisados e trabalhados através de estatística descritiva. Analisando as pontuações dos questionários respondidos pelos docentes, havia a possibilidade de a pontuação variar de no mínimo 50 pontos e no máximo 250 pontos. Verificou-se uma média de 194,04 pontos, evidenciando uma tendência a níveis positivos de autoimagem e auto-estima, existindo, no entanto, outras necessidades a serem satisfeitas, para chegarem a uma autorrealização.
\end{abstract}

\section{Palavras-chave:}

Autoestima. Autoimagem. Docentes. Educação básica. Pesquisa quantitativa.

\begin{abstract}
:
The aim of this study is to investigate levels of self-image and self-esteem of teachers working in basic education. The quantitative research used the Self Concept and Self-Esteem Questionnaire adapted by Stobäus (1983) from that developed by Steglich, in 1978, to collect data. 25 teachers participated in the study, aged between 26 and 58 years old, from a traditional private school in Porto Alegre, who operate in three levels of education (Early Childhood Education, Elementary and Secondary Education). Data were analyzed and worked through descriptive statistics. Analyzing the scores of questionnaires completed by teachers, that had the possibility to vary score between at least 50 points and at maximum 250 points, there was an average of 194.04 points, showing a tendency to positive levels of self-image and self-esteem. Nevertheless, there are other needs to be satisfied to reach a self-realization.
\end{abstract}

\section{Keywords:}

Self-esteem. Self-image. Teachers. Basic education. Quantitative research.

\section{Introdução}

Frente à crescente desvalorização da profissão docente, nos deparamos com o aumento gradual do número de professores que necessitam de licenças médicas para tratamentos de saúde, acompanhamento psicológico e psiquiátrico, apresentando manifestações psicossomáticas.
* > Professora de Educação Física, Doutoranda e Mestre em Educação/PUCRS, Especialista em Recreação, Lazer e Jogos Cooperativos. Colégio Marista Assunção. E-mail: karina.dohms@gmail.com. 
No entanto, apesar das diversidades enfrentadas na área da Educação, há alguns educadores que conseguem desenvolver sua auto-estima e autoimagem positiva. $\mathrm{O}$ desenvolvimento de tais aspectos depende tanto de situações externas quanto de situações internas do sujeito, devendo haver um maior investimento no que diz respeito ao autoconhecimento, neste caso, dos docentes.

O presente artigo surgiu a partir da Dissertação de Mestrado de Dohms (2011), servindo como base para uma discussão mais aprofundada a respeito da autoimagem e auto-estima de docentes, o que levou à elaboração deste texto, o qual buscou analisar a autoimagem e auto-estima de docentes que atuam na educação básica. Nessa perspectiva, o que ainda causa inquietação é a pouca preocupação com os temas da autoimagem e da auto-estima, que estão intimamente ligados ao mal/bem-estar docente, pois constituem a essência do desenvolvimento interior do ser humano em busca de autorrealização considerando que para chegar a um estado de autorrealização o ser humano necessita desenvolver anteriormente uma autoimagem e auto-estima positivas.

\section{Autoimagem, auto-estima e autorrelização}

O sistema educacional com o qual nos deparamos hoje já foi diferente. As prioridades e os objetivos eram outros, a participação da família era maior e as aprendizagens e conhecimentos transmitidos eram diferentes conforme as necessidades de cada família, sociedade e/ou época. Apesar de tantos progressos conquistados pela humanidade, ainda sofremos com os reflexos históricos do ensino. Entretanto, as prática de ensino vem caminhando na busca de tornar a Educação cada vez mais qualificada e valorizada.

$\mathrm{O}$ processo pedagógico gera muitas ansiedades, principalmente em docentes e discentes, que efetivam esta prática cognitiva na construção de conhecimentos. Além disso, os processos de ensino e de aprendizagem são regulados por aspectos subjetivos e pela afetividade, sendo a subjetividade resultado de um continuum de intensidades, que criam modos específicos e plurais de tornar-se sujeito, e das escolhas individuais: ou seja, ela é produto e produtora do sujeito em um processo que não cessa de acontecer.

Esses aspectos, juntamente com a auto-estima, a autoimagem e a autorrealização, retomam a relevância dos processos de ensino e de aprendizagem nos espaçotempos da sala de aula, esclarecendo que este termo "[...] se refere ao espaço e ao tempo de modo inter-relacionado. Nessa perspectiva, é necessário pensar fatos, processos fenômenos e situações-problema considerando simultaneamente as especificidades espaciais e temporais [...]” (UNIÃO MARISTA DO BRASIL, 2010, p. 26).

Atualmente, a grande maioria dos nossos estudantes já chegam com uma gama de conhecimentos superior à dos estudantes que ingressavam na escola há alguns anos atrás. Muitas foram as contribuições para isso, como: os avanços tecnológicos e o acesso às ferramentas tecnológicas, o aumento de serviços disponibilizados para aperfeiçoamento, como, por exemplo, os cursos de línguas estrangeiras, além de uma diversidade de atividades e recursos que hoje temos a nossa disposição. Todos esses recursos, que hoje estão a nosso dispor, nos proporcionam momentos de aprendizagem e, alguns, também oportunizam o ensinar, o buscar informações que poderão vir a se tornar conhecimentos e saberes mais específicos, tornando estes espaçotempos da sala de aula em um processo mais dinâmico - e que necessita, frequentemente, de atualizações. Com a configuração destes espaçotempos mais dinâmicos e inovadores, precisamos ficar atentos para não tornar os processos tão acelerados ao ponto de esquecer a importância das relações estabelecidas na sala de aula, especialmente no que diz respeito a afetividade.

Mosquera e Stobäus (2006a) percebem a afetividade como de fundamental importância para a vida humana, pois esta representa um dos aspectos mais relevantes e signi- 
ficativos para a constituição de seres humanos mais saudáveis e, principalmente, mais capazes para tomar decisões sábias e inteligentes.

Reconhecer suas próprias emoções pode levar o docente a uma compreensão maior, também, das emoções de seus educandos, e vice-versa. Assim, é favorecida a qualidade das relações interpessoais, criando um ambiente de ensino saudável e proporcionador de aprendizagens. Na medida que a pessoa reconhece a si mesma e é capaz de reconhecer o outro como um ser que também possui suas aspirações, inquietações e necessidades (estando ciente das suas próprias emoções e sentimentos); ela promove o seu próprio bem-estar, pois estes são aspectos fundamentais para uma relação benéfica entre docentes e discentes.

Para Mosquera e Stobäus (2006b, p. 85):

A auto-imagem e auto-estima realistas, no educador e no cuidador, são fundamentais para auxiliar nossos educandos em desenvolvimento, pois podemos acreditar mais em suas potencialidades, ao propor mais motivação em sala de aula, na situação de cuidado, ao colocar mais de nós mesmos no ambiente de trabalho/cuidado, ao sermos mais reais e parecermos menos o que não somos [...]

Esse desenvolvimento, da autoimagem e auto-estima, também está voltado para a formação pessoal, fazendo com que cada sujeito envolvido (re)descubra e (re)conheça no outro um igual, como seres pertencentes e fundamentais para os processos de ensino e de aprendizagem.

Já Freire (1983, p. 61) dizia que, aprendendo com as diferenças e percebendo suas semelhanças, ocorre esta interação entre o educador e os educandos, que "[...] co-intencionados à realidade, se encontram numa tarefa em que ambos são sujeitos no ato, não só de desvendá-la e, assim, criticamente conhecê-la, mas também no de recriar este conhecimento".

Além de favorecer o trabalho coletivo, o trabalho com o outro se efetiva, e fomenta a cooperação, na medida em que ambos se encontram na busca de alcançar objetivos comuns. Em um ambiente no qual prevalece o espírito de cooperação, o sucesso é compartilhado e o medo do insucesso diminui, ou até mesmo desaparece, pois valoriza-se mais o processo que os fins em si mesmos.

Ao educador cabe escolher a estrutura mais adequada para determinada situação de aula e integrá-la ao seu conteúdo ou tema proposto, pois não precisa, obrigatoriamente, utilizar métodos prontos, mas acima de tudo deve buscar seus próprios meios, aqueles com os quais (o professor) se identifica e que o deixam mais seguro para aplicar com naturalidade e confiança, através de estratégias simples. Desta maneira, pode transformar a prática pedagógica e criar um ambiente de ajuda mútua, respeitando as diferenças e promovendo responsabilidades compartilhadas.

Mosquera et al. (2006) destacam que um docente mais saudável, com melhores relações interpessoais, deve propiciar aos educandos e a si mesmo a autorrealização, presumindo ser alguém e realizando algo realmente relevante para si e para os outros.

Os processos de ensino e de aprendizagem se dão com a curiosidade, o encantamento dos educandos, e a forma de expressão do educador para com estes, visando despertar este encantamento nos educandos pela educação, pela aprendizagem, pelo saber. Desta maneira, é possível desenvolvermos padrões de comportamento positivos, levando os educandos a trabalhar com mais harmonia e compreensão, criatividade e cooperação, responsabilidade e preocupação com as demais pessoas, desenvolvendo empatia pelo próximo. A empatia é um sentimento de grande relevância, pois é a capacidade que uma pessoa tem de colocar-se no lugar do(s) outro(s). Consequentemente, ela amplia não só as qualidades das relações humanas, mas desperta na(s) pessoa(s) outros sentimentos e potencializam valores humanos, entre os quais estão a sensibilidade, a atenção, o respeito, o cuidado, a auto-estima, a confiança e a solidariedade. 
Mosquera et al. (2006, p. 3-4) citam Cooley, que chamou atenção para a relação entre o eu-pessoal e a sociedade, ressaltando que o eu e a sociedade nascem juntos, numa relação em que se dá a construção das subjetividades a partir da complexa e contínua socialização. A autoimagem, então, surgiria na interação com o social, como consequência das relações com os outros e das relações do sujeito consigo mesmo, o que daria a ele a capacidade de antecipar comportamentos e cuidar-se em suas relações com os outros, aprendendo a interpretar o meio ambiente e tentando ser o mais adequado às exigências que lhe são feitas e às que propõe para si mesmo. Estes autores ainda relatam que:

Ao perguntarmos a uma pessoa reflexiva que tipos de experiências puseram em sério risco sua auto-estima e auto-imagem, provavelmente descreverão alguma combinação algo em que tenham fracassado ou comentários negativos dos outros. A auto-imagem, diz ele, é mais o (re)conhecimento que fazemos de nós mesmos, como sentimos nossa potencialidades, sentimentos, atitudes e idéias, a imagem o mais realística possível, enfim, que fazemos de nós mesmos.

Por isso, é importante ressaltar as influências das relações no e para o desenvolvimento humano, especialmente no ambiente escolar, local em que os processos de ensino e de aprendizagem se efetivam, também, nas relações estabelecidas uns com os outros, num constante vir a descobrir, a interagir, a compartilhar, a vivenciar e a reconhecer a si mesmo e aos demais.

Visto que a autoimagem e a auto-estima estão fortemente atreladas ao conhecimento de si mesmo, o self - que se refere à construção do eu no ser para o outro -, elas são constantemente influenciadas por aspectos afetivos, cognitivos e sociais, mormente se positivos.

Recorda Damásio (2004, p. 119) que, a criação do self depende de uma estrutura fisiológica do sentimento, não sendo possível ter consciência, visto que alguns níveis necessários para produzir um sentimento de emoção são essencialmente os mesmos que o self e a consciência se baseiam. O autor acredita que "[...] criação do self depende, ela mesma, de uma estrutura fisiológica do sentimento e que sem self não é possível conhecer coisa nenhuma, não é possível ter consciência”. Segundo o autor:

Alguns dos níveis e ramos necessários para produzir um sentimento de emoção são precisamente os mesmos que são necessários para produzir o pronto-self, no qual o self propriamente dito e a consciência se baseiam. (DAMÁSIO, 2004, p. 156-157)

O conhecimento de Si mesmo (self) requer um reconhecimento dos próprios sentimentos, pois, ao ter esta noção, o ser humano é capaz de distinguir-se e de desenvolver mais sensibilidade, além de um melhor e mais positivo cuidado para consigo mesmo e para com os outros.

Conforme Timm, Mosquera e Stobäus (2008) uma melhor educação de si, que abrange cuidados para consigo, é aquela em que nos trabalhamos diariamente nas questões que vão desde nossa autoimagem e auto-estima até ao sentido que damos ao conceito de autorrealização.

O conceito de autoimagem está intimamente relacionado à imagem que o sujeito faz dele próprio, levando em consideração o que os outros dizem a seu respeito, o que acha que dizem dele e a imagem real que faz de si. Já a auto-estima, desenvolve-se primeiro a partir do outro, seguindo para o $\mathrm{eu}$, ou seja, emana do exterior, de fatores extrínsecos ao sujeito. Desenvolvendo a autoimagem e a auto-estima chegamos ao autoconceito, com vistas para a autorrealização. 
Cada pessoa se constitui no conviver, e este se dá a partir das relações estabelecidas com os outros. Mosquera et al. (2006) apresentam traços do que caracterizaria uma auto-estima positiva, quais seriam: a segurança e a confiança em si mesmo, possuir relações sociais saudáveis, o reconhecimento das qualidades próprias, a busca de felicidade, conseguir admitir que possui limitações, ser aberto e compreensivo, ter a capacidade de superar possíveis fracassos, ser crítico construtivo e, sobretudo, ser coerente e consequente consigo mesmo e com os demais.

Sendo a personalidade também construída através das relações interpessoais estabelecidas com outros sujeitos tidos como modelos, com os quais interagimos, pelo meio ambiente e pelas compensações que vamos constituindo nas relações ao longo de toda a vida, Maslow (1991, p. 31) destaca que:

[...] todas as pessoas de nossa sociedade (salvo umas poucas exceções patológicas) têm necessidade ou desejo de uma valoração geralmente alta de si mesmas, com uma base firme e estável; têm necessidade de autorespeito ou de auto-estima, e da estima de outros $[\ldots]$

Ainda que todas as necessidades estejam satisfeitas, pode-se esperar que o indivíduo desenvolva uma nova insatisfação e/ou uma nova preocupação para ser saciada. Mosquera e Stobäus (2006b) acreditam que a natureza da autoimagem, que é a base da auto-estima, está no conhecimento de cada pessoa a respeito de si mesma, bem como no desenvolvimento de suas próprias potencialidades, que fazem parte do processo de identidade. Em uma tentativa de autoatualizar-se e autorrealizar-se o tempo todo.

Assim sendo, podemos perceber a importância do autoconhecimento e o quanto este influencia no desenvolvimento de autoimagem e auto-estima mais saudáveis e positivas e na busca de autorrealização. Estes fazem parte de um processo ininterrupto, que ocorre durante toda a vida, e sofrem modificações de acordo com o momento de vida em que cada pessoa se encontra, de que forma lida e avalia as situações e os outros, pertencentes de suas relações.

Mosquera (1978), fazendo alusão a Ebling (1975), lembra que para o professor, tanto pessoal quanto profissionalmente, a consciência de estar fazendo algo importante e de estar ajudando os educandos a aprender e desenvolver suas potencialidades pode ser considerada como a maior fonte de autossatisfação e auto-estima.

Rogers (1997, p. 331-334) vê a tarefa do professor como aquela que deve criar um clima para facilitar a ocorrência de aprendizagens significativas podendo esta implicação ser desenrolada em subseções, tais como:

"Autenticidade do professor: a aprendizagem pode ser facilitada, segundo parece, se o professor for congruente. Isso implica que o professor seja a pessoa que é e que tenha uma consciência plena das atitudes que assume.

"Aceitação e compreensão: a aprendizagem significativa é possível se o professor for capaz de aceitar o aluno tal como ele é e de compreender os sentimentos que ele manifesta.

»Os recursos disponíveis: existem muitos recursos do conhecimento, de técnica, de teorias, que constituem matéria-prima a ser utilizada; [...] esses recursos, devem ser postos à disposição dos estudantes e não impostos.

"O motivo fundamental: sua função consistiria no desenvolvimento de uma relação pessoal com seus alunos e de um clima nas aulas que permitissem a realização natural dessas tendências.

" Algumas omissões: avaliação; conferências, palestras e exposições; pois as experiências e exames são colocados pela vida. 
Estes fatores, expostos pelo autor, destacam aspectos que, como tratamos anteriormente, podem vir a beneficiar o desenvolvimento de autoimagem e auto-estima mais positivas, como a conscientização e aceitação do professor em relação a si mesmo, o sentimento de empatia com seus discentes e a manutenção de um ambiente mais saudável, que favoreça boas relações interpessoais. Nessa perspectiva, estará proporcionando condições para um desenvolvimento de autoimagem e auto-estima positivas em todos os envolvidos no processo educacional.

Outro fator para o desenvolvimento da auto-estima é o de que o sujeito possua uma visão mais realista de si mesmo, podendo levar a desempenhos coerentes e eficazes, tornando-o muito mais seguro e consciente das próprias potencialidades e valores, como destacou Stobäus (1983).

De acordo com Maslow (1991, p. 345), uma pessoa com alta auto-estima e, também, segura manifesta sentimentos de forma amável, cooperativa e amistosa. É uma pessoa com alta/positiva auto-estima. Já a pessoa com alta auto-estima mas insegura não está tão interessada em ajudar os mais frágeis e consequemente seria mais negativa. Apesar de ambos possuírem alta auto-estima, manifestam-se de forma diferente, de acordo com as características de seu organismo. No entanto, lembra que, em geral, as pessoas com baixa auto-estima tendem a ser mais religiosas, mas obviamente, há outros fatores determinantes da religiosidade. Esse fato resulta da necessidade que os indivíduos têm de apoiar-se em uma fonte de fortaleza. Mosquera e Stobäus (2006b, p. 84) também dizem que:

Todo o ser humano tem necessidade de valorização positiva, ou auto-estima positiva, no sentido de mais real, e esta é aprendida mediante a interiorização, ou introjeção das experiências de valorização realizadas pelos outros para ela [...]

Lembrando que a auto-estima está intimamente relacionada à resiliência, pois, na busca de valorizações positivas, precisamos adaptar-nos às diferentes situações com que nos deparamos, mantendo o entusiasmo para então superá-las, restaurando sentimentos positivos. As maneiras para lidar com tais situações dependerão de cada sujeito e de suas peculiaridades.

Conforme Maslow (1962, p. 192-193), “[...] o ser humano é, simultaneamente, o que é e o que anseia ser [...]", demonstrando “[...] em sua própria natureza uma pressão por Ser cada vez mais completo, da realização cada vez mais perfeita da sua condição humana”.

$\mathrm{Na}$ condição de seres humanos, estamos num constante vir a ser, um ser que aprende, ensina, relaciona-se e também busca suprir suas necessidades e aspirações. A realização reside na motivação humana por ser melhor, mais feliz e mais pleno, no sentido de contemplar as dimensões que nos constituem enquanto humano: social, física, racional, emocional e espiritual.

Mosquera (1978, p. 83) acredita que a vida humana caracteriza-se em uma constante busca de significados, sendo que a realização do ser humano consiste no projetar-se além de si mesmo, criando um sentimento profundo acerca da sua integridade e do seu valor. Complementa dizendo que, “[...] a autoconcepção e a auto-realização são frutos de experiências qualitativas que damos às nossas vivências e ao nosso posicionamento no mundo".

Rogers (1997) entende que uma aprendizagem significativa é aquela que provoca modificações, seja no comportamento do indivíduo, na orientação da ação futura escolhida ou até mesmo nas atitudes e na sua personalidade, e que não se limita ao aumento de conhecimento, mas que transpõe todas as parcelas da existência.

Aprendemos, durante toda a vida, através das experiências e interrelações que estabelecemos, e somente somos capazes de nos transformar com aquelas que encontramos algum significado, para então projetarmos novas intenções para nossa realização. Salienta Maslow (1962, p. 193 ) que 
O homem fundamentalmente, não é moldado ou trabalhado numa condição humana, nem ensinado para ser humano. O papel do meio consiste em última análise em permitir-lhe ou ajudá-lo a realizar suas potencialidades, não as potencialidades do meio.

Ainda argumenta que é difícil definir a criatividade autorrealizadora, pois algumas vezes “[...] parece ser sinônimo da própria saúde, como foi sugerido por Moustakas”. Para este autor, saúde deve ser definida como “[...] a realização da humanidade plena de cada um, ou como o Ser da pessoa [...]", como se a criatividade autorrealizadora fosse sinônimo dessa característica definidora da humanidade essencial (p. 178).

Ainda para Maslow (1962, p. 247):

As fontes do crescimento e da plena realização humana estão, essencialmente, no íntimo da pessoa humana e não são criadas ou inventadas pela sociedade, a qual apenas pode ajudar ou dificultar o desenvolvimento da condição humana, tal como um jardineiro pode ajudar ou tolher o crescimento de uma roseira, mas não pode garantir que ela venha a ser um carvalho.

O meio em que o sujeito interatua influencia seus aspectos biológicos, psicológicos e sociais, mas como destaca Maslow, não é o definidor de sua realização enquanto humano. Suas aspirações, de certa forma, são inatas e caminham rumo a realização pessoal. Não podemos deixar de mencionar que algumas aspirações surgem por influências externas, sejam elas induzidas culturalmente ou, até mesmo, pelas relações que a pessoa estabelece socialmente.

Rogers (1997) crê que os seres humanos precisam de aceitação, e quando esta lhes é dada movem-se em direção à autorrealização. Também, salienta que Maslow dizia que os indivíduos autorrealizados possuem uma capacidade surpreendente de apreciação constante, fresca e ingênua dos bens fundamentais da vida, com fervor, prazer, encanto e mesmo êxtase, por mais que estas experiências, aos outros, possam parecer desgastadas.

Segundo Maslow (1991, p. 22), “[...] a pessoa autorrealizada, inclusive quando suas necessidades básicas estão satisfeitas, encontram que a vida é ainda mais enriquecedora e significativa porque podem viver, por assim dizê-lo, no reino do Ser". O autor ainda ressalta que as pessoas autorrealizadas possuem um autêntico desejo de ajudar a raça humana, pois sentem certa afinidade e vínculo com as pessoas como se fossem membros de uma mesma família.

Para Manestrina e Manestrina (1996, p. 13), “[...] a auto-realização engloba satisfações biológicas, aprendizagens de potencialidades para sobreviver física e socialmente, desenvolvimento da autonomia, independência e profundo sentimento de autodeterminação". Por fim, os autores citam que, para que o ser humano viva sua efetiva autorrealização, precisa que o seu ser e o seu fazer conjuguem-se no seu existir.

A conscientização da sua própria existência como ser humano, na interação entre aspectos que constituem o ser humano como tal, é que fornece os subsídios para que seja possível encontrar condições de favorecer o desenvolvimento de autoimagem e auto-estima positivas, em prol da melhor autorrealização pessoal possível em determinado momento. Isto faz com que cada sujeito almeje sentimentos positivos em relação ao seu eu, o que refletirá em todas as dimensões que o compõem ao longo de sua trajetória, quer pessoais, quer profissionais.

Pensando e refletindo sobre a profissão docente, percebemos o quanto o desenvolvimento de autoimagem e auto-estima mais positivas e realistas possíveis são vitais e inspiradoras para os processos de ensino e de aprendizagens. Quando docentes e discentes são estimulados a perceber e investir nesses aspectos surgem novas possibilidades que ampliam e aperfeiçoam os processos educacionais, tanto no âmbito pessoal quanto no relacional. 


\section{Indicadores de autoimagem e auto-estima de docentes que atuam em educação básica}

A pesquisa quantitativa utilizou para a coleta de dados o Questionário de Autoimagem e Autoestima adaptado por Stobäus (1983) daquele elaborado por Steglich, em 1978. Participaram da pesquisa 25 docentes, com idades entre 26 e 58 anos - havendo uma predominância dos 38 aos 47 anos de idade -, de uma escola tradicional de Porto Alegre, de ensino privado, que atuam três níveis de ensino (Educação Infantil, Ensino Fundamental e Ensino Médio), sendo os dados analisados e trabalhados através de estatística descritiva.

O Questionário de Autoimagem e Autoestima é dividido por aspectos, tais como: orgânicos, sociais, intelectuais e emocionais. Estes por sua vez são subdivididos e correspondem a algumas das questões do instrumento conforme especificação abaixo (STOBÄUS, 1983):

\section{Orgânicos:}

" Genéticos (questões de números 12, 19 e 21);

» Fisiológicos (questões de números 2, 5 e 23).

\section{Sociais:}

»Status sócio-econômico (questões de números 3, 7 e 33);

» Condições de família (questões de números 28 e 30);

" Realizações profissionais (questões de número 1, 4, 8, 9 e 16).

\section{Intelectuais:}

» Escolaridade (questões de números 6, 10 e 13);

» Educação (questões de números 12, 15, 19 e 38);

"Sucesso profissional (questões de números 11, 24 e 31).

\section{Emocionais:}

» Felicidade pessoal (questões de números 14, 18, 25, 27, 39 e 41);

" Bem-estar social (questões de números 26, 29, 32, 36, 45, 46 e 47);

"Integridade moral (questões de números 17, 20, 22, 34, 35, 37, 40, 41, 42, 43, 44, 48, 50).

Considerando as respostas dos docentes ao questionário, que teve o propósito de verificar níveis de autoimagem e de auto-estima, havia a possibilidade de a pontuação variar de no mínimo 50 pontos e de no máximo 250 pontos. Analisando as pontuações dos questionários respondidos pelos docentes foi possível verificar uma média de 194,04 pontos.

Nosso estudo constatou níveis considerados como mais positivos de autoimagem e auto-estima entre estes docentes pesquisados. A pontuação mínima constatada em nossa pesquisa foi de 141 pontos (apenas um professor) e o máximo de 222 pontos (dois professores).

A Tabela 1, apresentada a seguir, para um melhor entendimento, demonstra a classificação da pontuação dos docentes. A pontuação de cada pessoa se dá através da contagem dos pontos de suas respostas, progressiva ou regressivamente, conforme grade de apuração das respostas (STOBÄUS, 1983). 
Tabela 1 - Pontuação dos docentes em resposta ao Questionário de Autoimagem e Autoestima.

\begin{tabular}{l|c}
\multicolumn{1}{c|}{ Pontuação } & No de sujeitos \\
\hline de 141 a 161 pontos & 1 \\
\hline de 162 a 182 pontos & 5 \\
\hline de 183 a 203 pontos & 9 \\
\hline de 204 a 222 pontos & 10 \\
\hline Média: 194,04 pontos & 25 sujeitos \\
\hline
\end{tabular}

Fonte: Dados da pesquisa, 2013.

Nossa pesquisa verificou que o grupo participante da pesquisa apresentou uma média semelhante às encontradas nos estudos de Mosquera (2000) e de Mosquera e Stobäus (2001, 2003, 2006, 2009).

Nas questões correspondentes aos aspectos Orgânicos, chamam atenção as respostas dos sujeitos a duas questões que envolvem a memória (12 e 21), uma vez que acreditamos que todo professor gostaria de ter uma memória melhor. Quando perguntado se tinham uma boa memória (questão $\mathrm{n}^{\circ} 12$ ), a maioria dos docentes respondeu positivamente, apenas 4 responderam que às vezes e 1 respondeu que não. Já na questão $\mathrm{n}^{\circ} 21$, a pergunta foi: Gostaria de ter memória melhor?, e também a maioria respondeu positivamente (10 - sim, 1 - quase sempre, e 8 - às vezes).

Relacionado à memória, Perrenoud (2002, p. 146) diz que:

\begin{abstract}
Uma nova experiência, uma nova tentativa, um novo saber e um novo contexto talvez esclareçam retroativamente uma ação passada, alterem seu significado, situam-na em outra perspectiva. Sua representação pode se enriquecer em função de um trabalho deliberado de investigação, análise e reconstrução, ou em função de uma forma mais inconsciente, a qual depende do processo de racionalização e esquematização característico de nossa memória.
\end{abstract}

Stobäus e Mosquera (2010, p. 14) lembram que somos capazes de buscar informações “[...] em nossa(s) memória(s), através de vias que não somente a cognitiva. Retivemos um determinado detalhe via psicológica e emocional, e por aí a buscaremos ou ela é melhor buscada via social, e lembremos da repercussão social”.

Nas questões que correspondem aos aspectos Sociais destacaram-se as que estão relacionadas ao status socioeconômico (Tabela 2). Na questão de $\mathrm{n}^{\circ} 3$ apenas quatro docentes não consideram satisfatória sua situação financeira, 8 consideram às vezes, 5 quase sempre e 8 consideram satisfatória. Logo em seguida (no Questionário de Autoimagem e Autoestima), na questão de $n^{\circ} 7$ manifestam opiniões bem divididas, mas a maioria demonstra preocupação com sua situação financeira, respondendo: 7 - sim, 2 - quase sempre, 10 - às vezes, 3 - quase nunca e 3 - não. Também dentro deste aspecto, porém sobre as realizações profissionais, todos os docentes responderam positivamente às questões. 
Tabela 2 - Resposta dos docentes destacando duas questões referentes aos aspectos Sociais.

\begin{tabular}{l|c}
\multicolumn{1}{c|}{ Respostas à Questão no 3 } & No de docentes \\
\hline Sim & 5 \\
\hline Quase sempre & 5 \\
\hline Às vezes & - \\
\hline Quase nunca & No de docentes \\
\hline Não & 4 \\
\hline Respostas à Questão no 7 & 7 \\
\hline Qim & 2 \\
\hline Às vezes & 10 \\
\hline Quase nunca & 3 \\
\hline
\end{tabular}

Cremos que a preocupação financeira aqui comprovada remete a uma ideia futura, pois como seres humanos nos preocupamos em ter condições básicas como, por exemplo moradia e alimentação, para podermos manter boas condições futuramente, para nós mesmos e para nossas famílias.

No aspecto Intelectual, os sujeitos pesquisados demonstram gosto pelo aprender (os 25 responderam sim) e curiosidade em conhecer coisas novas (22 - sim, 2 - quase sempre e 1 - às vezes), bem como consideram que até agora conseguiram realizar o que pretendiam na vida (14 - sim, 8 - quase sempre e 3 - às vezes). Isso reforça uma característica da profissão docente, gostar de aprender e buscar novos conhecimentos a fim de enriquecerem suas práticas, principalmente com o avanço das tecnologias, em que o acesso às informações é muito rápido, além de chegar a um maior número de pessoas. Isso faz com que o professor também precise estar nesta constante busca, em constante formação.

No que diz respeito à formação de bons professores, em especial dos iniciantes, Perrenoud (2002) acredita que ela está intimamente ligada à formação de pessoas capazes de evoluir, de aprenderem com as experiências, refletindo sobre o que gostariam de fazer, sobre o que fizeram e sobre os resultados de tudo isso.

Já nas questões referentes aos aspectos Emocionais há duas questões que dividem as opiniões dos sujeitos da pesquisa. A pergunta de número 25, Preocupo-me muito comigo mesmo?, em que a maioria deles respondeu, respectivamente, às vezes (7), quase nunca (6) e não (4); e a de número 41, Sinto-me magoado quando os outros me criticam?, na qual os sujeitos responderam, respectivamente, sim (1), quase sempre (5), às vezes (9), quase nunca (7) e não (3).

Os sujeitos ainda demonstram preocupações quando encontram problemas, que refere-se a questão 20 (4 - sim, 5 - quase sempre, 12 - às vezes, 4 - quase nunca), mas sentem-se seguros em suas atitudes, resposta à questão 34 (11 - sim, 12 - quase sempre, 1 - às vezes e 1 - quase nunca). Quanto à pergunta de número 17: Sinto conflitos interiores?, 5 sujeitos responderam que sim, 14 - às vezes, 4 - quase nunca e 2 - não. A questão 50 perguntou: Se pudesse começar tudo de novo, gostaria de ter uma vida diferente?, e os sujeitos responderam 2 - sim, 6 - às vezes, 6 - quase nunca e 11 responderam que não. 
Mosquera (1978) ressalta que os relacionamentos podem parecer apenas como ligação de afetos, interesses ou intercâmbios, pois estes são os aspectos mais evidentes. Para tanto, em toda relação humana há um intenso sentimento de inquietação, o que leva à procura de significados e apreço. E, no caso dos docentes essas relações são produzidas não apenas pessoalmente, mas também profissionalmente, criando vínculos com discentes, colegas docentes, e demais membros que compõe a comunidade educativa. Lidar com todas essas relações é o grande desafio.

Ainda em relação aos aspectos Emocionais, é importante destacar uma citação de Damásio (2004, p. 156-157) que expõe:

Cada experiência da nossa vida é acompanhada por algum grau de emoção, por menor que seja, e esse fato é especialmente notável em relação a problemas sociais e pessoais importantes. [...] O fato é que as emoções, positivas ou negativas, bem como os sentimentos que se lhes seguem, tornam-se componentes obrigatórios das nossas experiências sociais.

Para tanto, não é demasiado ressaltarmos a importância de maiores investimentos no que diz respeito as emoções e sentimentos na Educação, uma vez que as relações estabelecidas de forma positiva servirão como estímulo para tornar os processos de ensino e de aprendizagem melhores e bem-sucedidos, assim como irão favorecer uma convivência saudável entre todos aqueles que participam de forma efetiva destes processos.

Maslow (1962), acredita que um professor e uma cultura não criam um ser humano; pois não podem inserir nele a capacidade de amar, de ser curioso, de filosofar, de simbolizar, ou até mesmo de ser criativo; mas sim, são capazes, de permitir, promover, encorajar, ajudar o que já existia em um embrião, para que este se torne autêntico.

Em total convergência, Rogers (1997) afirma que o máximo que um indivíduo pode fazer por outro é criar determinadas condições, a fim de tornar possível a aprendizagem, pois a pessoa não pode ser obrigada.

Assim, criar ambientes favoráveis para adequados processos de ensino e de aprendizagem também significa criar ambientes permeados pelo afeto e que despertem a motivação, visto que a motivação também gera satisfação. Na medida que o professor também consegue motivar seus discentes para aprender, suas aulas também lhe serão mais significativas e, consequentemente, um clima de bem-estar será instaurado, destacando, mais uma vez, como primordial para os processos educacionais, o desenvolvimento de sua autoimagem e auto-estima.

\section{Considerações finais}

Lembrando que o objetivo do estudo foi investigar níveis de autoimagem e auto-estima de docentes em uma escola tradicional de Porto Alegre, foi possível constatar, após a análise dos dados de pesquisa, que entre os sujeitos pesquisados há uma tendência a níveis positivos de autoimagem e auto-estima, existindo ainda outras necessidades a serem satisfeitas para chegarem a uma autorrealização.

Com a análise do Questionário de Autoimagem e Autoestima é importante salientar que a auto-estima dos docentes participantes da pesquisa está mais relacionada aos aspectos sociais, detacando-se o status socioeconômico, e aos aspectos emocionais, relacionado ao cuidado de si.

É de grande valia adotar ações adequadas que visem contribuir para melhoria da saúde docente, bem como desenvolver a autoimagem e auto-estima com vistas na autorrea- 
lização destes profissionais. Sendo que as instituições de ensino deveriam ser as primeiras a garantir este ambiente saudável, proporcionando apoio, acolhimento, desenvolvendo relações baseadas no afeto e no bem-estar.

Neste sentido, ressaltamos os estudos e contribuições que a Psicologia Positiva possibilita, sendo de fundamental importância seu conhecimento para então serem desenvolvidos nas instituições de ensino, como forma de estimular o bem-estar em seus educadores e colaboradores.

Além disso, recorrer e investir em constantes formações e na educação continuada, como forma de instrumentalizar melhor estes profissionais para o seu fazer diário, prático. Necessitamos rever a ideia de um maior investimento nos cursos de graduação, e sua melhora/aprimoramento é um dos fatores primordiais para combater uma possível situação futura de mal-estar docente. É importante ter em vista a efetividade de preparar, também, os novos profissionais para o mercado de trabalho, aproximando ainda mais a realidade plural encontradas nas escolas, nas salas de aula e na gestão.

Também, os responsáveis pela gestão educacional e pedagógica precisam promover um ambiente de apoio e acolhimento aos docentes, sendo capazes de solucionar os problemas que surgem diariamente nas instituições de ensino. Uma gestão qualificada possui papel fundamental para os professores, podendo contribuir na busca de melhores condições de saúde docente.

A relevância deste estudo está intimamente relacionada à atividade profissional dos docentes, ao desenvolvimento pessoal destes, e, consequentemente, para que se atinjam melhores resultados no processo de ensino e de aprendizagem. Não há como negar que os níveis de autoimagem e auto-estima de docentes podem vir a influenciar positiva ou negativamente as aulas, qualificando ou desqualificando a aprendizagem dos educandos.

Acreditamos que estudos sobre a autoimagem e auto-estima possam facilitar e apontar direções às pessoas, principalmente aos docentes, motivando-os a conviverem efetivamente com as diferenças e adversidades presentes na vida e nos contextos dos quais fazem parte, criando um ambiente respeitador e permitindo a valorização do potencial singular de cada um.

\section{Referências}

DAMÁSIO, António. Em busca de Espinosa: prazer e dor na ciência dos sentimentos. São Paulo: Companhia das Letras, 2004.

DOHMS, Karina Pacheco. Níveis de mal/bem-estar docente, de autoimagem e autoestima e de autorrealização de docentes em uma escola tradicional de Porto Alegre. 2011. 114 f. Dissertação de (Mestrado em Educação),- Pontifícia Universidade Católica do Rio Grande do Sul, Porto Alegre, 2011.

FREIRE, Paulo. Pedagogia do Oprimido. Rio de Janeiro: Paz e Terra, 1983.

MENESTRINA, Tatiana Comiotto; MAENESTRINA, Elói. Auto-realização e qualidade docente. Porto Alegre: EST, 1996.

MASLOW, Abraham Harold. Introdução à psicologia do ser. Rio de Janeiro: Eldorado, 1962.

. Motivación y Personalidad. Madrid: Ediciones Díaz de Santos, S.A., 1991.

MOSQUERA, Juan Jose Mouriño. O professor como pessoa. Porto Alegre: Sulina, 1978.

. Professores na Pós-Modernidade: narrativas da subjetividade docente. Relatório de pesquisa. Porto Alegre: Pós-graduação em Educação da PUCRS. 2000.

MOSQUERA, Juan Jose Mouriño; STOBÄUS, Claus Dieter. O mal-estar na docência: causas e conseqüências. Revista da ADPPUCRS, Porto Alegre, n. 2, p. 23-34, nov. 2001.

. O mal-estar na docência: causas e conseqüências. Relatório de Pesquisa. Porto Alegre: Faculdade de Educação da PUCRS, 2003. 
. Afetividade: a manifestação de sentimentos na educação. Educação, Porto Alegre, ano XXIX, n. 1, p. 123-133, jan./abr. 2006a.

. Auto-imagem, autoestima e auto-realização: qualidade de vida na universidade. Psicologia, Saúde \& Doenças, Lisboa, v. 7, n. 1, p. 83-88, jul. 2006b.

A formação do professor. Do mal-estar ao bem-estar na docência. Projeto de Pesquisa. Porto Alegre: PPGE-Faculdade de Educação da PUCRS, 2009.

MOSQUERA, Juan Jose Mouriño; et al. Auto-imagem, autoestima e auto-realização. Urevista, São Leopoldo, v. 1, n. 2, p. 1-13, abr. 2006.

PERRENOUD, Philippe. A prática reflexiva no ofício de professor: profissionalização e razão pedagógica. Porto Alegre: Artmed Editora, 2002.

ROGERS, Carl Ransom. Tornar-se pessoa. São Paulo: Martins Fontes, 1997.

STOBÄUS, Claus Dieter. Desempenho e autoestima em jogadores profissionais e amadores de futebol: análise de uma realidade e implicações educacionais. 1983. Dissertação (Mestrado em Educação),Universidade Federal do Rio Grande do Sul, Porto Alegre, 1983.

A neuropsicopedagogia e seus aportes para o auto-conhecimento e o trabalho. In: CONGRESSO BRASILEIRO DE PSICOLOGIA DA SAÚDE, 2., Uberlândia, 2010. Anais... Uberlândia: Universidade Federal de Uberlândia, 2010. p. 1-15.

TIMM, Edgar Zanini; MOSQUERA, Juan Jose Mouriño; STOBÄUS, Claus Dieter. Resiliência: necessidade e possibilidade de problematização em contextos de docência. Educação, Porto Alegre, v. 31, n.1, p. 39-45, jan./abr. 2008

UNIÃO MARISTA DO BRASIL. Projeto Educativo do Brasil Marista: nosso jeito de conceber a Educação Básica. Brasília, DF: UMBRASIL, 2010. 